\title{
Analysis on Influence of Internet Language on College Ideological Political Education
}

\author{
Wenhao Li \\ Wuhan University of Science and Technology \\ Wuhan, Hubei, China 430065
}

\begin{abstract}
With the continuous development of Internet technology, the network has become an indispensable part in our lives. As a kind of external form of Internet culture, Internet language has gradually become colleges' a new name card, which is both an opportunity and a challenge for college ideological and political education. [1] How to better promote college ideological and political education in the new period, and it requires us to have a comprehensive analysis of the influence on college ideological and political education by Internet language.
\end{abstract}

Keywords-Internet language; ideological and political education; influence

\section{INTRODUCTION}

Internet language is the product in the process of network technologies' continuous development, and a special form of language with characteristics of the times. "Internet language is a new and specific social dialect, because it not only has the unique users and communication situation, but also has a unique expression function." According to the research within academic cycle, it is generally believed that Internet language has a sense broad and a narrow sense. The Internet language in broad sense contains three aspects: network and information technology-related terminology (such as login, browser, modem, etc.), network-related special words (such as Netizen, surf the Internet, Internet users, etc.) and chat language used on the Internet. While the Internet language in narrow sense, only contains the chatting language on-line, namely the text, images and symbols used by the netizens in network chat software. [2] The Internet language of this study is in the narrow sense, which is the language carrier for expressing emotions while communicating on the Internet through a certain method in order to meet the network commun ication. Internet language is a product of the real language in network environment, which input the carrier by virtue of the keyboard, and add some of user's ideas based on the terms in real life, thus to spread in the network environment, and radiate to the real life.

\section{POSITIVE INFLUENCE OF INTERNET LANGUAGE ON COLLEGE IDEOLOGICAL AND POLITICAL EDUCATION}

Internet language is favored by college students thanks to its own characteristics, and at the same time, it has enhanced college students' attention on current politics and people's livelihood. The application of Internet language by college students has also provided powerful opportunity for the innovation of discourse power of ideological and political education.

\section{A. Enhance College Students' Attention on Current Politics and People's Livelihood}

The immediacy of network has provided convenient information channels for college students, but also made a wide variety of information come in succession. The simultaneous presentation of large quantities of information cannot help college students to focus on specific event information in-depth, but has cultivated and encouraged their reading habit of scanning. In the eyes of part of the college students, some of the concise, novel and humorous headlines can attract more attention and students' in-depth understand and reading compared with the report of the whole lengthy event. The Internet language about figures and events attract college students' deep concern by virtue of such method. For college students, the narration and mutual communication of hot issues using Internet language will arouse college students' curiosity, inspire college students' enthusiasm tap into events behind the terms and enhance college students' attention on current affairs on the one hand; on the other hand, the extended link of a certain entry by the Internet can also arouse college students' discussion on related or similar events, increasing college students' enthusiasm to be devoted to popular social events and attention on hot topics. Since 2010, several events such as "salt grabbing" " Radix Isatidis grabbing" have improved college students' ability of screening Internet public opinion, and enhanced their own ability to think independently, and form their own behavioral style of not to blindly follow others, which is of great benefit for college students' ideological and moral cultivation in the new era. With the rapid development of China's politics, economy and society in the new era, various problems appear continuously, all kinds of skepticism from the Internet come one after another, college students in the new era is in the such wave of public opinion. As a result, to maintain the correct value evaluation system and form a correct outlook on world, life and values, serious requirements have been proposed for college ideological and political education.

\section{B. Meet the Psychological Needs of College Students}

Colleges have made the transition of college students from individual to society come true. But in such a process of transition, various problems will appear in college students. The emergence of network has provided a harbor for the 
college students, satisfying college students' psychological needs.

The Internet language which is generated in colleges and is used extensively is the real reflection of college students' ideological changes in the new period. The current college students have better opportunities compared with before, namely having such a medium as network, they can acquire various knowledge more conveniently. But at the same time, they also face the more severe challenges. The huge employment pressure and the high living cost form the huge impact on college students' ideology. Internet language and relatively easy and anonymous environment of Internet have provided a way for college students to release their pressure, and they can also learn to communicate with others slowly in the network environment. [3] The application of Internet language by college students is blind sometimes, but it has achieved the purpose of communication, and enables themselves and others to be relaxed and joyful.

Internet language is conducive to college students' emotion releasing in the virtual world of cyberspace by virtue of its unique form of expression. Their own characteristics can also been added, to make Internet language has its own unique color, and give full expression to their subject value. At the same time, in the virtual community on the Internet, sense of identity is easy to be generated among college students who use Internet language. As a result, Internet language can also meet college students' sense of belonging, which is good for improving college students' sense of identity toward campus and class as well we the class cohesiveness.

\section{Beneficial to the Innovation of College Ideological and Political Discourse System}

College ideological and political education discourse is the language used by college ideological and political educator in order to achieve the educational purposes used in the process of ideological and political education, which is a link between ideological and political education and the education objects. For a long time, the ideological and political discourse has been the language carrier in promoting socialist theory with Chinese characteristics, and constantly helps college students to establish a common ideal of socialis $m$ with Chinese characteristics. At the critical moment of deepening reform comprehensively and achieving the great rejuvenation of Chinese nation, college ideological and political discourse power is at a critical moment of innovation. A reasonable and normative application of Internet language as well as the expansion and improvement of college ideological and political discourse system, are conducive to further combination of college ideological and political education in the new era and to move forward.

In recent years, the identity of theory courses of college ideological and political education is gradually decreased, which is closed related to the population of Internet language in college students. Students argue that the theory courses of ideological and political education are too boring, lack of appropriate interaction, and they cannot be attracted by the courses. However, the related ideological and political educators themselves are short of understanding toward network-related language, so they cannot effectively use Internet language in the courses or they themselves have a resistance toward Internet language, which have impacted the smooth implementation of theory courses of college ideological and political education. As a product of the new era, Internet language is spread widely among college students. The innovation of discourse power of college ideological and political education should make full use of Internet language, so as to enable ideological and political education be recognized by college students.

\section{NEGATIVE INFLUENCE OF INTERNET LANGUAGE ON COLLEGE IDEOLOGICAL AND POLITICAL EDUCATION}

Due to the virtuality and anonymity of the network, and the Internet language itself is free, so in the process of network language dissemination, some negative factors are inevitably involved in while adding the positive factors, which has influenced college students' physical and mental health as well as college ideological and political education. As a result, how to seek advantages and avoid disadvantages has become a problem to be solved.

\section{A. College Students' Identification for Mainstream Culture Is Weakened}

After all, the Internet language is different from the language for daily conversation. As a product developed from the Intemet, it is inevitable for Internet language to deviate from the mainstream culture in some places. If college students trust this concept gradually while using the Internet language, it is bound to weaken their acknowledgement toward mainstream culture. [4] At the same time, the Internet language also contains a large number of languages and behaviors that worship material (for example, the new meaning of "Tuhao" and behaviors showing off their wealth on Internet), which will promote the spreading of pragmatis $m$ and utilitarianis $m$ among college students, seriously affect the formation and perfection of college students' outlook on the world, life and values.

Chinese traditional culture advocates respecting the aged and taking good care of children. "If you can respect other old people while supporting your own elders, and show love to other children while taking care of your own children, then you can control the world" is a true reflection of this tradition. In the transition period of society, a lot of social problems did happen in China, for example, students helped the elderly who has fallen down but was extorted. In 2006, the treatment of "Peng Yu case" made people staggering. The extreme transmission capacity of the network has greatly magnified negative impact of the case. Afterwards, some people say on the Internet that they will not help the elderly who have fallen down immed iately, but will seek relevant witness to guarantee his/her innocence first of all. But at the same time, the Internet also convey some positive social events to us, such as the people who moved China each year, are all the representatives of traditional culture, and all of them show us the profound and long-lasting traditional culture. Traditional culture is the treasure of Chinese nation, but the spreading of negative Internet language make some college students refuse traditional culture to a certain extent, thinking that traditional culture has disconnected with the current social development. 


\section{B. College Students' Legal and Moral Consciousness Is Diluted}

While protecting the netizens' privacy, the virtual network has also resulted in the breeding of Internet language violence. Internet language violence refers to the network users attack other people or other organizations using vulgar language on some network platforms, which is a soft violence. Although the Internet language violence will not bring personal or property damage to the victims, it will bring a great loss of reputation and mentally. [5] Especially some portal sites and Internet marketers usually use the "insider", "confidential", "shock" and other words to attract the attention of Internet users for the click rate, and then control the direction of public opinion of the network event. For college students, because they are inexperienced, so they are very easy to be guided by Internet public opinion, and become the "accomplice" of network violence. For example, during the bird flu period in 2013, some criminals ru mored that Radix Isatidis can prevent bird flu on the Internet. A lot of network users prefer to believe it and spread this massage. Ultimately it resulted in the public's panic and rush to purchase the Radix Isatidis, which had seriously affected the market order. In 2014, after the airplane of Malaysia Airlines lost contact, groundless slanders toward Malaysia Airlines were filled on the Internet, accusing accidents often take place in this airline company and declared openly that they will not take the flight of this company, and guided the Internet users to conduct network public opinion attack toward the Malaysian government intentionally. In 2015, after the event of "Eastern Star" cruise ship, someone quickly challenged relevant authorities' poor rescue on the Internet, and guided Internet public opinion to openly question government's credibility. In recent years, the frequent network "human flesh" search incidents have set off an alarm bell for network personal safety. The Internet language violence has brought about serious consequences. But because of the anonymity of the Internet, some backstage evils haven't been treated appropriately, and it will end up with nothing definite. If we allow such incidents to continue, college students' moral and legal awareness is bound to be weakened.

\section{Effect Communication between College Students and Educators Is Effected}

As a new product, Internet language quickly won the favor of college students and has become a common language within the group. But the ideological and political educators know less about Internet language, thus teachers and students lack the common language and they are unable to communicate better. On the one hand, educators shall play the leading role in ideological and political education. But the Internet language has caused barrier between educators and education objects. As a result, the educators' leading role in this process has been greatly weakened. On the other hand, the acceptance of Internet language by college students will make the students feel the normal ideological and political education boring, hindering the interaction in the process of education interaction and adding communication barriers between the two sides.

\section{CONCLUSION}

As the initiative side of college ideological and political education, the ideological and political educators often pay attention to the Internet language from the academic perspective due to their identity of educators, and their understanding toward Internet language is focused on the theoretical level with relatively less application in practice, and there is hardly no application of it in the ideological and political education course. College student are the passive party in ideological and political education, willing to accept new things, preferring the Internet language and willing to use, but their understanding toward Internet language is mostly superficial, having more understanding of the forms, structure, the meaning behind of the Internet language, with relatively more application in practice. This has resulted in the incomplete equivalence of the information as well as the deficiency of common discourse system between educators and education objects in the process of ideological and political education process. Teachers tend to teach theory, yet students are more interested in practice, leading to the ineffective ideological and political theoretical courses. Some students lack of interest in the courses, which has made teachers' leading role in the course missing, which is not conducive to the interaction in the theory courses of college ideological and political education.

\section{REFERENCES}

[1] Opinion on Further Strengthening and Improving Ideological and Political Education by CPC Central Committee and State Council [N]. People's Daily, 2014-10-14.

[2] An Zhiwei. Multi-perspective Study on Internet Language [M].Shanxi: ShanxiPeople's Publishing House, 2012:35-67.

[3] Liu Yali. Analysis of Psychological Factors for Netizens' Network Behavior [J]. Journal of Henan University: Social Science Edition, 2011(2):131-136

[4] Zhang Chunyan, Xie Tao. Discussion on Influence on College Ideological and Political Education by Internet Language [J]. Bridge of Century, 2011(9):120-121 .

[5] Wang Jing. Influence on College Ideological and Political Education by Internet Language [J].The Science Education of Article Collects, 2012(35):16-17. 